\title{
Improvement of Reciprocating Internal Combustion Engines on The Basis of New Designs Timing Mechanisms
}

\author{
Sergey Sergeevich Dragunov \\ MOSCOW STATE UNIVERSITY OF MECHANICAL ENGINEERING (MAMI) \\ Bolshaya Semenovskaya str., 38, Moscow, Russian Federation
}

Keywords: Internal combustion engine (ICE), valve train, variable valve timing (VVT), engine efficiency, exhaust gas recirculation (EGR), spring loaded slide valve.

Abstract. This article is devoted to answering the question of what should be the valve timing of the internal combustion engine in the future.

\section{Introduction}

The most important parameter of the engine is its specific power, because it provides acceleration and maximum speed. From an economic point of view the most important parameter is the specific fuel consumption. From the point of view of ecology it is the minimization of harmful substances in exhaust gases.

The authors of many publications try to find a compromise solution, which will provide the best combination of the above parameters on the basis of new designs timing mechanisms.

Adequately all options was considered in the article H. Hong et al. «Review and analysis of variable valve timing strategies - eight ways to approach» [1]. This review is based on the analysis of 36 different publications. The general conclusion is that only a mechanism with variable valve timing can best meet all of these requirements. However, some authors argue that the most wide adjustment range ensures the so-called camless mechanisms, in which the movement of the valves is carried out directly by an electric actuator or hydraulic with electric control.

Why did not one camless engine is not used in a batch production of cars? We will try to answer this question.

\section{Analysis of the operation of the valve.}

\section{Traditional timing with the cam shaft.}

Movement of the valve should be split into four stages.

1) Movement with acceleration in the direction of the opening;

2) movement with deceleration in the direction of the opening;

3) movement with acceleration in the direction of the closing;

4) movement with deceleration in the direction of the closing.

At the first and second stages, when the valve opens, the kinetic energy of the flywheel transforms into potential energy of the spring. At the third and fourth stages, when the valve closes, the potential energy of the spring partially transforms into kinetic energy of the flywheel. As this takes place the part of the reserved potential energy goes on overcoming of forces of friction. Thus, there is a partial return of energy to the flywheel.

Mechanical losses in the internal combustion engine are about $20 \%$ of the indicator power [2]. Moreover, the friction losses in the timing in two times less than that of the crank and connectingrod assembly [2, p.40] and accounts for approximately $8 \%$ of all friction losses.

Therefore, the total loss of useful work performed traditional gas distribution mechanism with the camshaft is of the order of $20 \%$. Therefore, the efficiency is $\eta=0.8$.

\section{Camless mechanisms of timing}


In Camless mechanisms of timing the movement of the valve is carried out directly by the solenoid armature or by the rod of the hydraulic cylinder. Friction loss in this case is minimal, because there is no normal (perpendicular) force and can be neglected.

To calculate the required power servo actuator it is necessary, first of all, determine the force of inertia of the valve together with the electromagnet core or together with the piston rod in the hydraulic cylinder.

The calculation of the force of inertia is given by:

$$
\mathrm{F}=\mathrm{m} \cdot \mathrm{a},
$$

where $\mathrm{m}$ - the total mass of the valve together with the armature or with a rod, a - acceleration.

The acceleration valve on the first stage corresponds to the angle of rotation of the crankshaft approximately $45^{\circ}$. If you take the crankshaft rotation speed at $3000 \mathrm{rpm}$, the time of acceleration valve $\mathrm{t}_{\mathrm{a}}$ will be $2.5 \mathrm{~ms}$.

If you take the movement during the first stage as a uniformly accelerated, the acceleration can be determined by the formula:

$$
\mathrm{a}=\frac{2 \cdot \mathrm{S}_{\mathrm{half}}}{\mathrm{t}_{\mathrm{a}}^{2}}
$$

where $S_{\text {half }}$ - is the half of the valve stroke.

The acceleration of the valve in this case will be $1280 \mathrm{~m} / \mathrm{s}^{2}$. If the total mass of the valve and electromagnet core is $-0.2 \mathrm{~kg}$, the force of inertia will be $256 \mathrm{~N}$.

The required mechanical power without friction loss can be determined by the formula:

$$
\mathrm{N}=\frac{\mathrm{F} \cdot \mathrm{S}_{\text {half }}}{\mathrm{t}_{\mathrm{a}}}
$$

For speed of $3000 \mathrm{rpm}$ is required mechanical power of 410 watts. Since the electromagnet is a converter of electrical energy into mechanical energy and its efficiency rarely exceeds $50 \%$, the electrical power consumed from the power source is two times higher, i.e. about 800 watts. If it is necessary to increase the speed of two times, then power consumption is increased four times.

If return spring is used, the power consumption increases even twice on the first stage of the valve.If the return spring is not used, then the power consumption in the second, third and fourth stages of the valve.

In the camless systems with electromagnets a double conversion of energy takes place. In a generator, mechanical energy is transformed into electricity, and in the solenoid the electric energy is converted into mechanical energy.

In this case, the electromagnet does not have the ability of recovering electric energy.

Therefore, these systems have a low efficiency $\eta<0.4$.

The question arises, how to increase efficiency?

\section{The timing mechanism with the spring loaded slide valve}

In 2012 and 2013, the author has done research work in the framework of the grant RFBR №12-0800012, and was investigated fundamentally new timing mechanism with slide valve making an oscillatory motion. The design is protected by RF patent for useful model №123462 [3].

The main goal was to improve the parameter that determines the filling of the cylinder and is called "time-section", and determines the specific power of the engine.

For this purpose, instead of the intake and exhaust valves has been set one rotary slide valve, which is in the middle position opens up access to the spark plug, when rotated in one direction opens the outlet, while turning in the opposite direction opens the inlet. Longitudinal section of the construction shown in figure 1.

For reversing the angular velocity was used return springs, made in the form of Archimedes spirals and separately shown in figure 2 . 
To rotate the valve, the actuator of the magnetoelectric type is used, which is compared to a conventional electromagnet has a higher efficiency and, most importantly, has the ability to switch so as the mode of the motor so a generator of electric current.

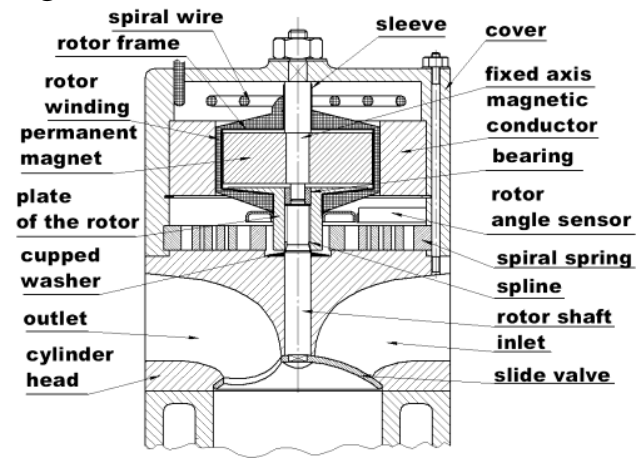

Figure 1

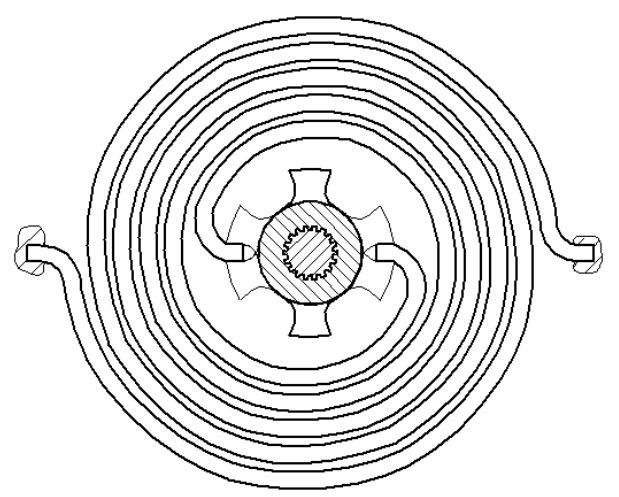

Figure 2

The principle of operation of the new design are shown in figure 3 , the top of which is conventionally shown the dependence of the piston speed of the angle crankshaft and the lower angular velocity of the slide valve.

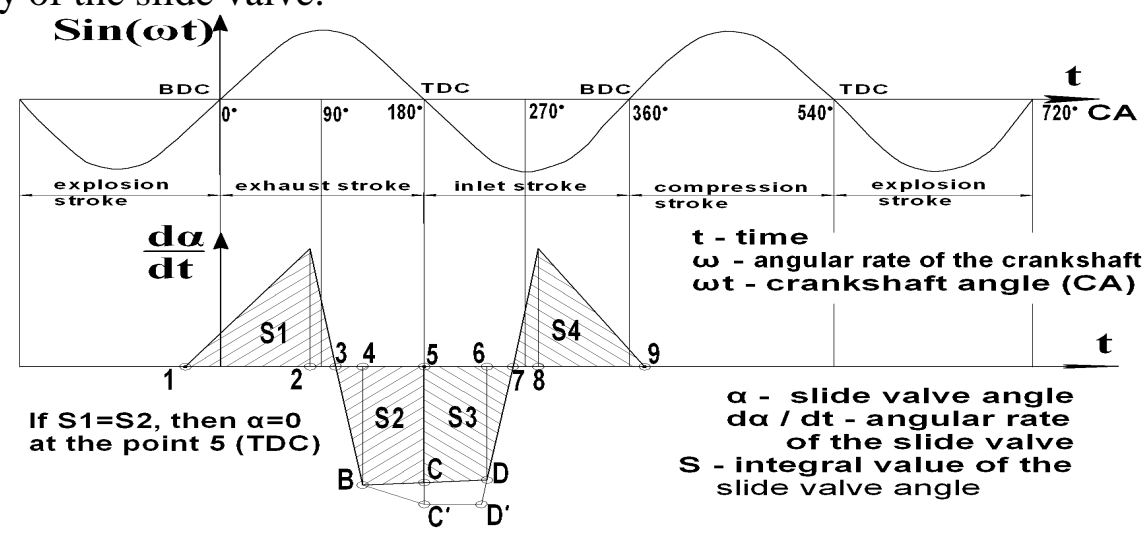

Figure 3

At the time interval $1-2$ acceleration of the slide valve occurs in the direction of the outlet opening, the drive operates in the mode of the motor. Friction losses occur only at the time interval 1 - BDC, when the cylinder holds the residual gas pressure.

At the time interval 2 - 3 slide valve is braked and its kinetic energy is converted to potential energy of swirling springs. At the time interval $3-4$ slide valve accelerates, and the potential energy of the springs goes into the kinetic energy of the slide valve. At the time interval $4-6$ the free movement of the slide valve occurs by inertia.

Points B, C, C', D, D' show the corrective effect of the automatic control system. This ensures the regulation of the internal exhaust gas recirculation. At the time interval $4-5$ the outlet is closing. At the time interval $5-6$ the inlet is opening. 
At point 5 the piston is at TDC, and the valve in the middle position, when both the inlet and outlet are closed. This case corresponds to the maximum engine power. In this case, square shapes $\mathrm{S} 1$ and $\mathrm{S} 2$ must be equal (point $\mathrm{C}$ ).

If the square of the shape $S 2$ is greater than the square shape $S 1$ (point $C^{\prime}$ ), then the slide valve will slip by the average position slightly before the piston will be at TDC. In this case, part of the exhaust gases will be emitted into the intake manifold, which is called internal exhaust gas recirculation. This mode reduces the amount of nitrogen oxides in the exhaust gases, while reducing engine power.

If the square of the shape $\mathrm{S} 2$ is smaller than the square shape $S 1$, in this case the valve will be in the middle position after the piston will pass TDC and starts an intake stroke. In this case, part of the exhaust gas will be sucked back from the exhaust manifold into the cylinder. This mode corresponds to throttle-free power control and reduce pumping losses. One of these three options can be obtained by changing the magnitude of the pulse applied to the rotor winding at the time interval $1-2$ and using the correction pulses on the time interval $4-5$.

At the time interval 6 - 7 slide valve is braked, and its kinetic energy is converted to potential energy of swirling springs. At the time interval $7-8$ slide valve accelerates, and the potential energy of the springs goes into the kinetic energy of the slide valve. At the time interval $7-8$ the actuator switches to generator mode and braking the slide valve and the generated electric energy is stored in super capacitors for later use. The energy loss in this case is about $50 \%$.

\section{Comparative analysis}

For the comparative analysis of the effectiveness of the developed design with traditional timing mechanism $\mathrm{OHV}$ was selected single-cylinder four-stroke engine with a displacement of $200 \mathrm{cc}$ LIFAN168F2.

The most expensive elements of the new design were permanent magnets of neodymium-ironboron required for the stator, and super capacitors needed for system recovery of electrical energy on the return stroke of the actuator.

The cost of a new engine with rotary slide valve was 9 times higher than the cost of the engine LIFAN168F2. Therefore, under the current price super capacitors and permanent magnets of neodymium-iron-boron new design can not compete with a traditional $\mathrm{OHV}$ engine series production.

\section{Summary}

Engines with conventional timing mechanisms such as OHV, SOHC and DOHC have ceased to satisfy the current requirements on exhaust emissions and fuel consumption in operation. Substantial reduction of harmful exhaust gas components can be achieved only by variable valve timing (VVT) at different engine operating modes.

Most major manufacturers have implemented in the production such systems based on traditional valve trains with camshafts, but in many publications cited studies of the so-called shaftless or camless mechanisms. In such systems, valves are operated by electric or hydraulic actuators. Such systems have a large range of variable valve timing, but by parameters such as cost, reliability, durability, compactness and economic feasibility can not compete with systems based on the cams.

Fundamentally new direction, it is the replacement of valves on a rotary valve, commits no rotational or translational motion but oscillating motion relative to the axis of the cylinder. However, the use of electric power for this valve is not rational.

Therefore, it is necessary to examine the possibility of using cams desmodromic type. One cam should accelerate the slide valve during opening the outlet, and the other must brake it at the stage of closing the inlet and return the kinetic energy in the flywheel.

\section{Acknowledgements}


This work was supported by the Federal State Institution "Russian Foundation for Basic Research" [Grant 12-08-00012-a].

\section{References}

[1] Hong, H., Parvate-Patil, G. B. and Gordon, B. Review and analysis of variable valve timing strategies - eight ways to approach Proc. IMechE, Part D: J. Automobile Engineering, 2004, 218:1179.

[2] Putintsev S.V. Mechanical losses in piston engines: chapters of construction, calculation and testing E-learning edition http://wwwcdl.bmstu.ru/e2/putintsev1.pdf.

[3] Utility patent number 123462 Russian Federation, the IPC F01L 7/00. Engine Timing combustion engine spool type Dragunov S., Borisov N., Novikov, A., Novikova A., Kapustin G., applicant and patentee Moscow State Engineering University (MAMI). № 2012197649/06 appl. 03/01/2012, publ. 27.12. 2012, Bull. №36. 